\title{
CORRESPONDENCE
}

\section{REMOVAL OF CORNEO-SCLERAL SUTURES}

\section{To the Editorial Committee of the BRITISH JOURNAL OF OPHTHALMOLOGY}

SiRs,-I am grateful to Mr. H. B. Stallard for his interest in my short contribution on the removal of corneal sutures and for his apt comments. I ought to mention that the object was to draw attention to certain advantages in using a knife and not to convey that the procedure was one of my own invention; indeed I learnt the method from my colleague, Mr. J. Sherne.

The thing that hath been is that which shall be, and that which is done is that which shall be done: and there is no new thing under the sun. Is there anything whereof it may be said 'See this is new?' It hath been already of old time, which was before us. Ecclesiastes, 1, ix and $x$.

I confess I did not know that Mr. Stallard had been using a knife, but I am pleased to hear that he does so with success.

32 Park SQuARe, LEEDS, 1 : I am, Sirs, your obedient servant, Peter Wilson.

September 6, 1958.

\section{REFERENCES}

Stallard, H. B. (1958). Brit. J. Ophthal., 42, 507.

WILSON, P. (1958). Ibid., 42, 248.

\section{BOOK REVIEWS}

Refraction of the Eye and its Anomalies. (La refraccion del ojo y sus anomalias.) By E. Gil Del Rio. 1957. Pp. 592, 335 figs, bibl. Tip. Cat. Casals, Barcelona.

The author's object is to correlate theoretical conclusions regarding accommodation with clinical findings so as to make the book available to a wide circle of readers. The approach is encyclopaedic: the introductory chapters cover the history, not only of the study of accommodation, but also that of light, and there are references to subjects as far apart as the crystal lenses of Niniveh and the Compton Effect encountered in nuclear physics. There is a simple but sound chapter on the elements of physical optics, simplified treatments of prisms, simple and compound lenses, and their aberrations. This is followed by a brief chapter on ocular anatomy (which contains a charming "open eye" diagram). Theories of accommodation are reviewed, particular attention being paid later to measuring techniques. Chapter 13, which deals with subjective procedures of measuring ocular refraction, is, in many ways, the most instructive of all, because it contains a succinct description of material usually flung far apart. Numerous clinical aspects are considered in detail, special attention being given to new developments in contact lens technique.

One or two minor criticisms have to be put on record. The references give a somewhat erratic impression. Only some of the authors are believed to have first names, their surnames are frequently mis-spelled both in the text and in the bibliography, and one French authority is referred to with profound respect although he has never done any work on ocular refraction and produced only one study on visual physiology. The illustrations are not uniform in quality. On the whole, however, the book can be recommended as useful. 